\title{
Characterization Analysis of PVDF Thin Films Fabricated Using Deep Coating Machines
}

\author{
Ambran Hartono $^{a^{*}}$, Suparno Satira ${ }^{\mathrm{b}}$, Mitra Djamal ${ }^{\mathrm{c}}$, Ramli $^{\mathrm{d}}$ \\ ${ }^{\mathrm{a} D e p a r t m e n t ~ o f ~ P h y s i c s ~ F a c u l t y ~ o f ~ S c i e n c e ~ a n d ~ T e c h n o l o g y, ~ I s l a m i c ~ S t a t e ~ U n i v e r s i t y ~ S y a r i f ~ H i d a y a t u l l a h, ~ J 1 . I r . H . J u a n d a ~ 95 ~}$ \\ Ciputat Jakarta, Indonesia \\ ${ }^{\text {b.c }}$ Theoretical High Energy Physics and Instrumentation Research Group, Faculty of Mathematics and Natural Sciences, \\ Institut Teknologi Bandung, Jl. Ganesa 10 Bandung 40132, Indonesia \\ ${ }^{\mathrm{d}}$ Department of Physics, Faculty of Mathematics and Natural Sciences, Universitas Negeri Padang, \\ J1. Prof Hamka, Padang 25131, Indonesia \\ *Email: ambranhartono@yahoo.com
}

\begin{abstract}
Development of Polyvinylidene Fluoride (PVDF) thin film manufacturing technologies is rapidly increasing. Various fabrication methods continue to evolve. In this paper described about the fabrication of PVDF thin films using deep coating. Fabrication of PVDF films made for several samples with variations of temperature and duration of heating. Piezoelectric properties of PVDF as well as the fraction of the value of $\beta$ is the focus of which is discussed in the paper. The amount of beta fraction samples will determine the quality of thin films made. To see how much the value of the beta fraction sampled sample characterization using FTIR and XRD. Characterization of the results obtained is then performed calculations to determine how much beta fraction of the sample. From the calculations, the fraction of beta to increase the heating temperature of $70^{\circ} \mathrm{C}$ to $110^{\circ} \mathrm{C}$ in a row is: $37 \%, 38 \%, 44 \%$, $50 \%$ and $58 \%$. Further more for variations in the length of time to warm up 10 minutes, 20 minutes and 30 minutes fractions beta values obtained by $34 \%, 48 \%$ and $60 \%$. These results indicate that the PVDF thin films fabricated using deep coating method has produced samples of PVDF films with good piezoelectric properties. Of research is well known that the optimum annealing temperature was $110^{\circ} \mathrm{C}$ and the optimum length of heating time is 30 minutes.
\end{abstract}

Keywords: Annealing temperature, $\beta$ fraction, Deep Coating, Heating time, Piezoelectric PVDF

\section{Introduction}

The piezoelectric effect of Polyvinylidene Fluoride (PVDF) was first raised by Kawai in 1969. At that time also began an investigation and study the properties of molecules and co-polymers with well [1]. PVDF is a plastic material in a group of fluorine polymers, these polymers typically used for a variety of applications that require a high level of purity, strong and resistance to solvents. These polymers are easily formed because the polymer has a low melting point of about $177^{\circ} \mathrm{C}$. Low density and low cost compared with other fluorinated polymers [2].

Polyvinylidene fluoride is usually in the form of powders, pellets, sheets and wires used for the insulator. One advantage of PVDF polymers are easily formed and is usually used in the chemical industry, semiconductor, medical and electronic industry such as lithium ion batteries [3]. PVDF polymer can be synthesized from VDF monomer gas through a free radical polymerization process, after which it can be done filming by pressing method, casting and spreading. PVDF polymer structures are named from 1.1 difluoroethylene ( $\mathrm{CH} 2$ - $\mathrm{CF} 2)$ while the monomer is $\mathrm{CH} 2=\mathrm{CF} 2$ [4]. Solid form of polyvinylidene fluoride molecules can be grouped in three phases, namely phase structure of beta, alpha and gamma. Beta phase has a structure (YYYY), alpha phase with the structure (TGTG) and gamma phase with the structure (TTTGTTTG) [4]. General phase structure of PVDF is negligent phase [1]. Polyvinylidene fluoride has been developed is that the structure of the beta phase, this is due to the phase PVDF has a most excellent piezoelectric properties.

This phase has the form of a molecular chain with a zigzag conformation types that are all trans-planar (YYYY) with a small deflection caused by fluorine atoms which are not bound in the nearest monomers (Hasegawa, 1972) [5]. Crystal form is orthorhombic $\beta$ phase which according to Hasegawa analysis on this phase has a unit cell $\mathrm{a}=8.58 \AA, \mathrm{b}=4.91 \AA$, and $\mathrm{c}=2.56 \AA$ with its melting point range $191^{\circ} \mathrm{C}$ and $212^{\circ} \mathrm{C}$ [6].

The form of this phase is a very important phase for piezoelectric applications. The chains are arranged in the form of $\beta$ along the longitudinal direction of the unit cell. Each bond carbon atoms ( $\mathrm{C}$ ) with a fluorine atom ( F ) has a certain direction and the resultant dipole moment of carbon atoms are also bonded to hydrogen $(\mathrm{H})$ has a resultant dipole moment direction is the direction of the resultant bond between carbon atoms with fluorine.

$\beta$ phase has a crystal meetings of $1.97 \mathrm{~g} / \mathrm{cm} 3 \mathrm{based}$ on the model of the unit cell Hasegawa et al. Elastic modulus at all trans chain has been calculated by Tashiro et al. Value of the elastic modulus $2,37 \times 10^{11} \mathrm{~N} / \mathrm{m}^{2}$ (planar zigzag) and $2.24 \times 10^{11} \mathrm{~N} / \mathrm{m}^{2}$ (due to deflection). This value is the result of Tashiro experiment. As for the $\beta$ phase dipole moment for yourself that $7 \times 10^{-28} \mathrm{C} \mathrm{cm}^{3}$ [7].

The form alpha phase is the most common form. In 1966 Lando, et al [8] the first time gives the value of the unit cell for $\alpha$ phase is: $\mathrm{a}=9.66 \AA, \mathrm{b}=4.96 \AA$ and $\mathrm{c}=4.64$ $\AA$ with an angle $\alpha=\beta=\gamma=90^{\circ}$. Alpha phase development for further research conducted by several researchers such as Bachmann and Lando [9] (structural analysis using X-ray analysis), Kobayashi, et al [10] 
(through the analysis of infrared and Raman Spectroscopy) and Hasegawa, et al [11] by Farmer, et al [12] (calculation of potential energy). From the analysis of the structure by Lando and Bachmann are studying the structure of $\alpha$ phase using X-ray analysis found that the unit cell $\alpha$ phase has a primitive orthorhombic space group. The unit cell for $\alpha$ phase is $\mathrm{a}=4.96 \AA, \mathrm{b}=9.64 \AA$, and $\mathrm{c}=4.62$ with $\alpha=\beta$ all angles $=\gamma=90^{\circ}$.

The form of $\alpha$ phase has two molecular chains with glide -type conformation tgtg' with $\mathrm{T}=179^{\circ}$ and $\mathrm{G}=45^{\circ}$. Each connected by a center of symmetry which have an inverse relationship to one symmetry, thus resulting in a total dipole moment of the entire crystal electricity were mutually exclusive. That is, for the entire orientation of the dipole - dipole form builds the resultant non-polar crystals. This form has a molecular chain with dipole - dipole polarization of random, so that the overall crystal is nonpolar. In conformation TGTG ' there is no strict strain between the fluorine atoms and only minimal strain on some fluorine - hydrogen chain, this causes a conformational TGTG ' has the lowest potential energy among all polymorphic known [13]. In the unit cell has a density of crystalline phase $\alpha$ of $1.92 \mathrm{~g} / \mathrm{cm}^{3}$. Elastic modulus to its chain conformation TGTG' the $7,7 \times 10^{10} \mathrm{~N} /$ $\mathrm{m}^{2}[15]$.

Various methods have been developed previously in the PVDF thin film manufacturing technology include calendaring method [18], coating, spreading [19] and evaporation $[20,21,22]$. In this paper explained how the results of the PVDF thin film manufacturing method development is deep coating method. In this method of making do PVDF film with the mechanism coating solution on a glass substrate preparation through the dyeing process. The advantage of this method is the coating process is done by machines (motor), which can move up and down and simply operational. Velocity of the motor can also be arranged as needed. With this method it is possible to be obtained with a thin film obtained quality thin film with good quality.

\section{Experiment}

PVDF thin film technology development as a biosensor material continues to grow as well as the manufacturing. Various methods have been developed previously as methods of casting, calendaring, and spreading, hot press certainly have done with a variety of advantages and disadvantages. Nor has the characteristics of the sample and the costs to be incurred. An alternative method was developed here in addition to the above method is the method of deep coating. This method is very simple and allows for the resulting sample of PVDF films with characteristics quite well. In addition, this method has a system of simple equipment and easy operation system.

Operational system of deep coating machine is very easy and simple because it does not require complicated skills. Construction stage is very easy that the success rate is also high. In addition, the manufacture of thin films by this method does not require huge costs and the required equipment is also readily available.

PVDF thin film manufacturing method also allows obtaining thin films with homogeneous thickness. Equipment deep coating machine has three main components, namely supply system, driving the motor and speed control. The composition of the deep coating machine can be seen in Figure 1.

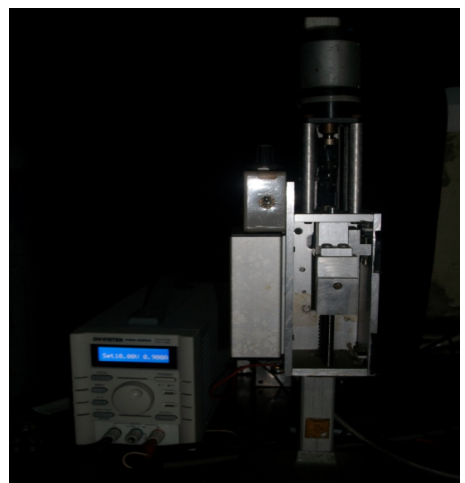

Figure 1. Deep coating machine instrument [23]

In this method the samples were made with glass immersion technique for coating solution preparation. Motor system of the machine moves up and down at a pace that can be controlled and adjusted. With the system settings on the speed of the motor is possible to obtain samples with a homogeneous thickness. Samples PVDF films made here made for some variety and some variations of temperature warming long heating time. This is done to see the trend of the sample characteristics and the optimum value of $\beta$ fraction of the variation of temperature and duration of heating. To determine the value of the PVDF sample $\beta$ fraction characterization was carried out using FTIR and XRD.

\section{Results and Analysis}

\subsection{Results}

Obtained from experiments carried out several pieces of PVDF thin film samples of three different concentrations of the solvent, the solvent concentration for $10 \%, 15 \%$ and $20 \%$. Thin films obtained results shown in Figure 2.

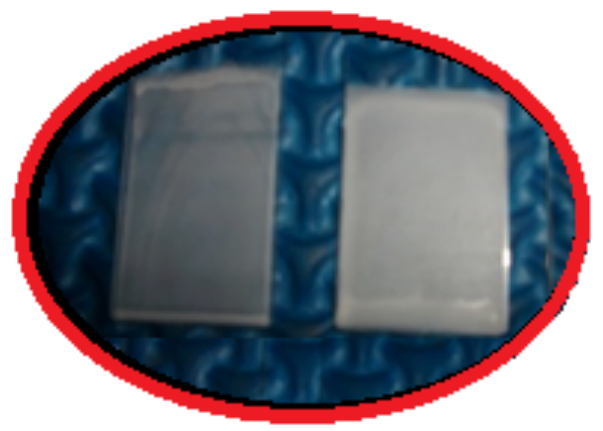

Figure 2 PVDF film sample

Further samples of the three types of concentration obtained using FTIR testing to see baseline characteristics of PVDF film sample. This was done to see the extent of the percentage area of the sample crystal PVDF films. IR spectra of the three types of samples for solvent concentration of $10 \%, 15 \%$ and $20 \%$ shown in Figure 3. 


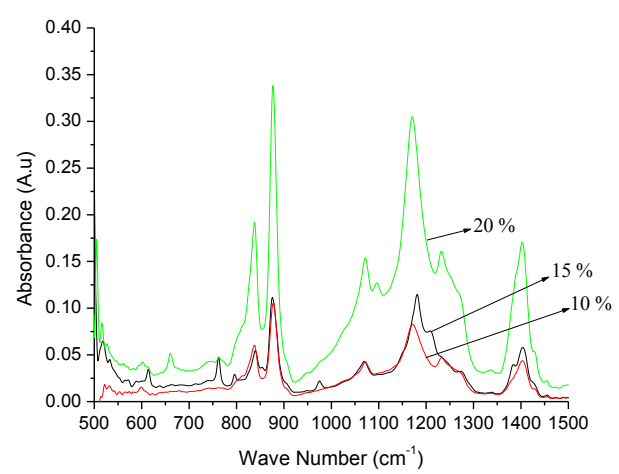

Figure 3 PVDF sample spectra for three different concentrations of solvent

After the initial characterization of the sample is then performed using the FTIR characterization using XRD. This characterization is done to determine how much beta fraction of PVDF thin film samples was produced. This characterization was performed after heating a thin film with 5 different annealing temperatures is $70^{\circ} \mathrm{C}$ to $110^{\circ} \mathrm{C}$. The results of the characterization of the samples obtained shown in figure 4 below.

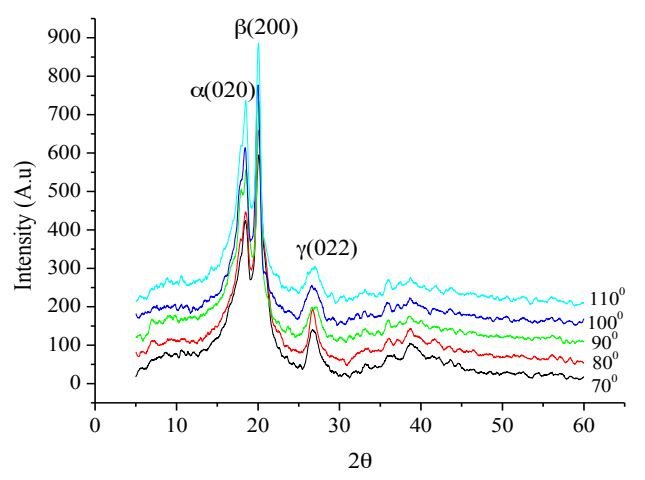

Figure 4 Diffraction pattern for the PVDF sample heating temperature $70^{\circ} \mathrm{C}$ to $110^{\circ} \mathrm{C}$

XRD results of the optimization of sample heating to $100^{\circ} \mathrm{C}$ and $110^{\circ} \mathrm{C}$ temperature. This optimization testing of films for three different annealing of time in a row 10 minutes, 20 minutes and 30 minutes. XRD characterization results of three different warm-up periods are shown in Figure $5 \& 6$ respectively

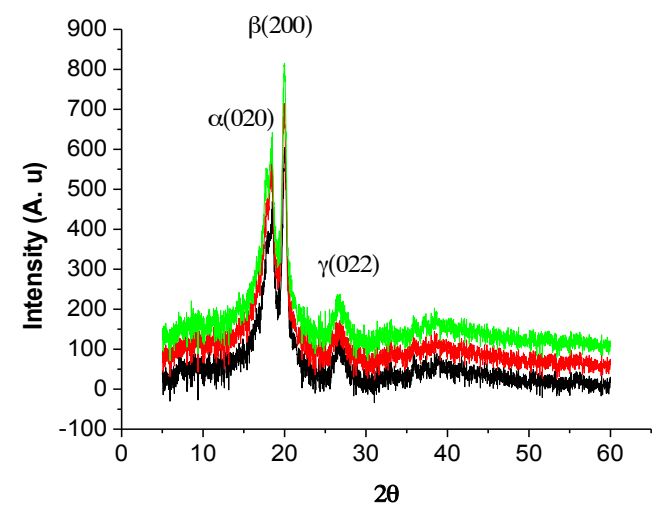

Figure 5 Diffraction pattern for the sample with the heating temperature $100^{\circ} \mathrm{C}$ with three different annealing times.

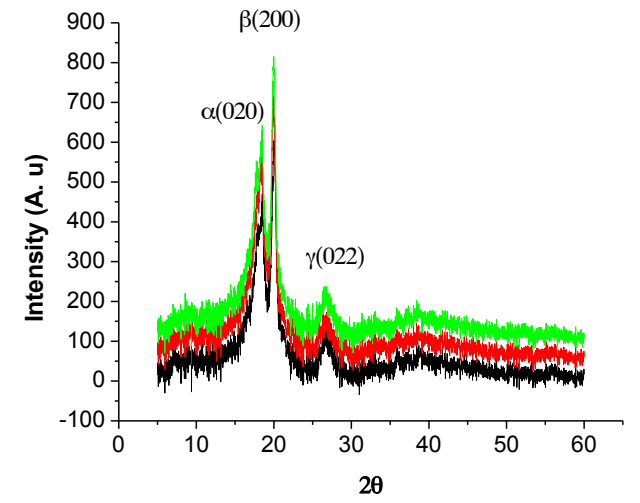

Figure 6 Diffraction pattern for the sample with the heating temperature $110^{\circ} \mathrm{C}$ with three different heating times.

Of characterization has been performed on samples of PVDF thin films for a variety of conditions and treatments, the next step analysis to determine the level of success of the fabrication process and the results obtained PVDF film making. Characterization and experimental results and calculations to determine the beta fraction of PVDF thin film samples is done by using equation 1 [23].

$$
F(\beta)=\frac{A_{\beta}}{1.26 A_{\alpha}+A_{\beta}} \times 100 \%
$$

Beta fraction calculation PVDF films with concentration of $10 \%, 15 \%$ and $20 \%$ respectively were obtained by $31 \%, 39 \%$ and $44.5 \%$. Meanwhile, for the beta fraction results for samples with annealing temperature $70^{\circ} \mathrm{C}$ to $110^{\circ} \mathrm{C}$ respectively obtained by $37 \%, 38 \%, 44 \%$, $50 \%$ and $58 \%$. While the calculation of beta for a fraction of PVDF film sample with time-varying warming 10, 20 and 30 minutes fractions beta values obtained by $34 \%$, $48 \%$ and $60 \%$.

\subsection{Analysis}

\subsubsection{FTIR Characterization}

FTIR characterization of the results that have been conducted on the sample as shown in Figure 8, it is seen that the area of the sample crystals obtained on a sample with $20 \%$ solvent concentration. It was as he had done by Lanceros and colleagues. That the optimum solvent concentration is $20 \%$.

\subsubsection{XRD Characterization}

Hereinafter for the characterization of the samples that have been optimized for solvent concentration of $20 \%$ by varying the annealing temperature optimum temperature is obtained at temperatures of $110^{\circ} \mathrm{C}$. This is consistent with the theory that annealing temperatures have a big impact on beta fraction of the sample as shown in the equations of mathematical relationships 2 [23] below:

$$
P-P_{r}^{0}={ }^{X} \varepsilon_{0} E+d X+p\left(T-T_{0}\right)
$$


Equation 2 indicates that the increase in temperature can increase the polarization dipole moment. This led to increased beta fraction of the sample. While the length of time the optimum heating obtained at the time of 30 minutes. This suggests that homogeneous heating is achieved at the time.

\section{Conclusion and Recommendations}

\subsection{Conclusions}

From the experimental results and the calculations have been done, the fraction beta of $44.5 \%$ for the optimum solvent concentration of $20 \%$, the fraction of beta for optimum $110^{\circ} \mathrm{C}$ annealing temperature by $58 \%$ and for 30 minutes the optimum heating time by $60 \%$.

\subsection{Recommendations}

In future research should really look more solvent concentration to obtain the optimum concentration, also make and design HVDC amplifier $20 \mathrm{KV}$ power supply for poling machine to increase of sample beta fraction.

\section{Acknowledgment}

Our thanks to the LP2M UIN Syarif Hidayatullah Jakarta on financial support in the implementation of this research.

\section{Reference}

[1] H. Kawai,. Piezoelectricity of polyvinylidene fluoride, Japan. J. Appl. Physics. 8, pp 975- 976, 1969.

[2] en. Wikipedia. Org/wiki/polyvinylidene_fluoride)

[3] Kawai. H, Polyvinylidene fluoride, Japan. J. Appl. Phys.8, 1969, 1975

[4] Lovinger Andrew, Poly-(vinylidene Fluoride), Bell Lab. New Jersey, 1981

[5] Hasegawa, R., et al, Polymer J., 1972, 3, 600

[6] Diana Sari, Pembuatan dan Karakterisasi Piezoelektrik PVDF dengan metode Spin Coating dalam pelarut N, N-Dimethylcetamide dan N, N-Dimethylformalide, ITB, 2004

[7] Tadokoro, H, Structure of Crystalline Polymers, John Willey and Sons, 1979

[8] Lando, J. B., Olf, H. G. and Peterlin, A., J. Polymer. Sci., A-1, 4, 1966, 941
[9] Bachmann, M. A. and Lando, J. B., Macromolecules, 14, 1981, 40

[10] Kobayashi, M., Tashiro, K. and Tadokoro, H. Macromolecules, 8, 1975, 158.

[11] Hasegawa, R., Kobayashi, M. and Tadokoro, H., Polymer J., 3, 1972, 591

[12] Farmer, B. L., Hopfinger, A. J. and Lando, J. B., J. Appl. Phys., 43, 1972, 4293

[13] Takahashi, Y. and Tadokoro, H., macromolecules, 13, 1980, 1317

[14] Rike Yudianti dkk 1996, Pengaruh Tegangan dan Waktu Poling terhadap Konstanta Piezoelektrik dari Film PVDF yang ditarik Buletin IPT No. 1 Vol. 11 Puslitbang Terapan LIPI Bandung

[15] Tim R. Dargaville, et. al , Characterization, Performance and Optimization of PVDF as a Piezoelectric Film for Advanced Space Mirror Concepts, SANDIA

[16] Wada,Yasaku and Reinosuke Hayakawa, Piezoelectricity and pyroelectricity of Polymer, Department of Applied Physics, Faculty of engineering, University of Tokyo, 1976 REPORT, SAND -6846, 2005.

[17] Wikipedia.com. Biosensor. Situs Web Wikipedia English

[18] Ambran, Mitra Djamal, Suparno Satira, Herman, Ramli, Edi Sanjaya. AMPC Journal, Effect of Mechanical Treatment Temperature on Electrical Properties and Crystallite Size of PVDF Film, 3, pp 71-76, 2013.

[19] V. Sencadas, V.M. Moreira, S. Lanceros-Mendez, A. S. Pouzada and R. Gregorio Jr. $\alpha$ - to- $\beta$ Transformation on PVDF Films Obtained by Uniaxial Stretch, Materials Science Forum Vols. 514-516, pp 872-876, 2006.

[20] Harsha, Principles of Physical Vapor Deposition of Thin Films, Ch02 Final Proof, 11, pp. 2005.

[21] Kwang Min Kim et.al. Effect of Evaporation Temperature on the Crystalline Properties of SolutionCast Films of Poly(vinylidene fluoride)s, Korean J. Chem. Eng., 20(5), pp 934-941, 2003.

[22] Herman, Susumu UMEMOTO, Takeshi KIKUTANI and Norimasa OKUI, Chain Length Effects on Crystal Formation in Vinylidene Fluoride Oligomers, Polymer Journal, Vol. 30, No. 8, pp 659-663, 1998.

[23] Ambran, Mitra Djamal, Suparno Satira, Herman, Ramli: Preparation of PVDF Film Using Deep Coating Method for Biosensor Transducer Applied, Proc. $3^{\text {rd }}$ (ICICIBME), pp. 408-411, 2013. 